\title{
Marco Estrada Saavedra \\ Alteraciones comunicativas: democracia, medios de difusión y la Asamblea Popular de los Pueblos de Oaxaca
}

\section{Introducción}

Una manera de introducir el tema de este capítulo puede ser recordando lo sucedido el $1^{\circ}$ de diciembre de 2004, día en que Ulises Ruiz Ortiz asumiría el cargo de gobernador del estado de Oaxaca. En esa fecha, Ruiz Ortiz convalidó la toma de las bodegas del periódico Noticias, ordenada por José Murat, el anterior mandatario, por parte de supuestos "comuneros" del municipio de Santa Cruz Amilpas. Como resultado de estas acciones fallecería una persona. No contento con lo anterior, el flamante mandatario orquestaría más adelante, en cooperación con un sindicato cercano al régimen prísta, un pseudo conflicto laboral en torno al contrato colectivo de trabajo de Noticias, con el fin de desaparecer un medio crítico e incómodo para su gestión. Ello derivaría en el cierre violento del diario por más de un año (Martínez Vásquez 2007: 36; Osorno 2007: 29).

Esta "anécdota" condensa a la perfección la relación que el gobierno actual de Oaxaca entablaría en el sexenio (2004-2010) con los opositores, en general, y con los medios de comunicación, en particular. He referido estos hechos porque nos dan luces para entender el significado político y social de la "toma de los medios" por parte de la Asamblea Popular de los Pueblos de Oaxaca (APPO) durante el conflicto de 2006.

A pesar de su importancia, las relaciones entre medios de comunicación y movimientos sociales han sido un tema muy poco estudiado en la sociología (Neidhardt 1994). En América Latina se ha puesto más bien atención a la configuración y redefinición del espacio público por parte de los actores colectivos (Bolos 2003; 2008; Cunill 1999; Estrada Saavedra 1995). Para el caso específico de la APPO, la "toma de los medios" en aquel candente verano de 2006, no ha mere- 
cido hasta ahora gran atención. Únicamente existe un trabajo sociológico que se ocupa de tan inusual e importante evento (Zires 2009). Por lo demás, la producción científica en torno al conflicto oaxaqueño ha sido magra, debido, en parte, a la relativa cercanía temporal que aún guardamos con aquellos sucesos. ${ }^{1}$ Como es natural, han predominado hasta este momento las publicaciones periodísticas, testimoniales, partidistas y de denuncia de violación de los derechos humanos (Beas Torres 2007; CCIODH 2007; Denham/C.A.S.A Collective 2008; Giarracca 2008; Martínez Vásquez 2007; Osorno 2007; Sotelo Marbán 2008), así como una notable producción de DVDs y CDs (Mal de Ojo/Contraimagen 2007; SNTE-Sección XXII/CNTE/ Radio Plantón 2007; Videohackers 2007). Aunque estas publicaciones se caracterizan por su falta de análisis sociológico y politológico, el material que contienen, sin embargo, es sumamente rico en información, imágenes y audios, por lo que son, de verdad, una fuente primaria fundamental para el estudio de la "Comuna de Oaxaca".

En este escrito buscaré responder las siguientes cuestiones: 1) ¿qué funciones cumplieron los medios de difusión "tomados" en la organización y movilización de la APPO? 2) ¿Cómo operaron y realizaron estos su trabajo informativo? Y 3) ¿cuál fue la relación entre los medios de difusión y el público appista? No obstante, antes de abordar estas preguntas, delinearé, de manera sucinta, el marco teórico-metodológico utilizado. ${ }^{2}$

1 Estudios académicos sobre los antecedentes del conflicto social y la APPO se encuentran en Cortés (2006), algunas colaboraciones en el número 24/25 de Cuadernos del Sur (2007) y en Martínez Vásquez (2009).

2 El material empírico de este escrito es producto del trabajo de campo que, desde 2008, llevo a cabo junto con la Dra. Silvia Bolos, en el marco de un proyecto de investigación sobre la constitución, organización y movilización de la APPO. Los lineamientos generales de esta investigación pueden consultarse en Bolos y Estrada Saavedra (2010). Deseo agradecer a la Universidad Iberoamericana y al Consejo Nacional para la Ciencia y la Tecnología por el financiamiento a nuestro trabajo. Asimismo doy las gracias a las fundaciones Alexander-von-Humboldt y Thyssen por la beca que me han otorgado como científico visitante en el Lateinamerika-Institut de la Freie Universität Berlin durante 2010. Con este estipendio he podido tener el tiempo y los medios necesarios para escribir este capítulo. 


\section{La APPO como un sistema de protesta}

En términos teóricos y metodológicos, concibo a la APPO no como un movimiento social, sino, más bien, como un "sistema de protesta". Este es una forma especial de los sistemas sociales, ${ }^{3}$ que se caracteriza por su constitución y producción mediante comunicaciones orientadas al conflicto. Estas comunicaciones se expresan temáticamente como movilizaciones de protesta en contra de diferentes oponentes (como el gobierno, las organizaciones eclesiales, las empresas, los medios de comunicación) o de las consecuencias no previstas de la operación de los sistemas de funciones de la sociedad (como la política, la economía, la ciencia o el arte). ${ }^{4}$

La complejidad de un sistema de protesta puede ser aprehendida por medio de la distinción de diferentes niveles de análisis. En efecto, mediante la diferencia sistema/entorno puede observarse cualquier sistema de protesta tanto en sus elementos, procesos, funciones y estructuras internos como, también, en relación a sus comunicaciones externas, interpenetraciones y acoplamientos estructurales con otros sistemas sociales (incluyendo los sistemas de funciones) de su entorno. Esta distinción fundamental ha de complementarse ulteriormente con otras tres más: la interacción, la organización y la sociedad. ${ }^{5}$ Mientras que la última, vista analíticamente, pertenece al entorno del sistema de protesta, las primeras dos distinciones tienen que ver con su constitución interna. En otras palabras, los participantes en el sistema de protesta pueden ser observados 1) ya sea en las interacciones cotidianas de sus respectivos medios sociales o mundos de vida, 2) como miembros de la organización sistémica en sus diferentes

3 Sobre el concepto de sistema social, véase Luhmann (1987).

4 Sobre la concepción de los "movimientos de protesta" de la teoría de sistemas, véase Ahlemeyer (1989; 1995); Hellmann (1996; 1998; 2000); Japp (1984; $1986 a ; 1986 b ; 1990)$ y Luhmann $(1992 ; 1996 ; 1998)$. Aunque emparentada con ella, mi modelo analítico varía de manera significativa con respecto a la concepción alemana. En este texto no me es posible, sin embargo, desarrollar estas diferencias. Sobre el tema véase Estrada Saavedra (2008).

5 Cualquiera que conozca la obra de Niklas Luhmann, sabrá que estas distinciones hacen referencia a tres tipos fundamentales e irreductibles de sistemas sociales (Luhmann 2005). Como no me siento obligado a seguir la ortodoxia "bielefeldiana" ni a hacer un culto improductivo, sociológicamente, a la "gran teoría", echo mano del instrumental conceptual de la teoría de sistemas para comprender y explicar, teórica y empíricamente, los sistemas de protesta. 
roles, posiciones de autoridad y relaciones de poder entre sí, o bien 3) como un unidad colectiva inserta en un conflicto con, al menos, un oponente y entablando relaciones de alianza y oposición con diferentes actores, grupos, organizaciones e instituciones. Esta complejidad le permite al sistema de protesta referirse, al mismo tiempo, a diversos sistemas de funciones y a sus respectivas organizaciones.

La APPO puede ser considerada teóricamente como un sistema de protesta porque: 1) se diferencia de su entorno; 2) logra su autopoiesis creando estructuras propias de comunicación, organización, movilización, producción y distribución de recursos y bienes colectivos; 3) crea su propia forma: la protesta; 4) construye su propia perspectiva de observación: la crítica sociopolítica y la denuncia contestataria; 5) elabora sus propios mecanismos de conducción (élites y liderazgos), reclutamiento (motivación y selección de miembros) e identidad (diferenciación del entorno); 6) entabla alianzas y produce redes de interacción y comunicación con otros sistemas de protesta, organizaciones, formadores de opinión pública, organizaciones no gubernamentales, etc.; 7) inicia eventos de protesta y conflicto con otros sistemas sociales, especialmente con las organizaciones de los sistemas de funciones, por ejemplo universidades, empresas, iglesias, partidos políticos, diarios, etc.; y, 8) critica los efectos de la diferenciación de los sistemas sociales. ${ }^{6}$ En este sentido, la APPO está compuesta por diferentes subsistemas especializados (como por ejemplo, los de la dirección política, la organización, la seguridad, la protesta simbólica o el de los medios de difusión) ${ }^{7}$ que, en su conjunto, conforman este sistema de protesta.

En relación a su composición organizativa y al origen de sus elementos constituyentes, se puede diferenciar a la APPO metodológicamente en tres segmentos: 1) la Sección 22 del Sindicato Nacional de Trabajadores de la Educación (SNTE), 2) las organizaciones populares y 3) los sectores no organizados o "independientes" de la

6 Siguiendo la enumeración anterior, los puntos 1 a 5 corresponderían a los niveles de análisis de la interacción y la organización, mientras que el 6 y 7 al de la sociedad.

7 Estos subsistemas especializados hacen referencia, respectivamente, a la Asamblea General, la movilización colectiva coordinada, las barricadas, los colectivos de artistas y los medios tomados. 
población ${ }^{8}$. Esta tríada de segmentos se encuentra, por su parte, internamente diferenciada en distintos grupos, fracciones, tendencias políticas y corrientes ideológicas, por lo que resultaría reduccionista suponer una homogeneidad del sistema de protesta, en general, y de los diferentes subsistemas, en particular. Esto implica, por tanto, que

8 Como el Frente Amplio de Lucha Popular (FALP), el Consejo Indígena Popular de Oaxaca (CIPO), el Frente Popular Revolucionario (FPR), la Organización Indígena de Derechos Humanos de Oaxaca (OIDHO), el Comité Democrático Ciudadano (CODECI), el Consejo de Defensa del Pueblo (CODEP), la Organización de Pueblos Indígenas Zapoteca (OPIZ), el Ayuntamiento Popular de San Blas Atempa, Nueva Izquierda de Oaxaca.

También conformaron la APPO los sindicatos agrupados en el Frente de Sindicatos y Organizaciones Democráticas de Oaxaca (FSODO), entre los cuales se encuentra el Sindicato de Trabajadores y Empleados de la Universidad Autónoma Benito Juárez de Oaxaca (UABJO) y la Sección 35 de la Secretaría de Salud. Asimismo se integraron un conjunto de organizaciones no gubernamentales como Educación Alternativa (EDUCA), el Comité de Apoyo al Movimiento Popular de Oaxaca (CAMPO), la Liga Mexicana de Derechos Humanos (LIMEDH), la Red de Derechos Humanos de Oaxaca, la Casa de la Mujer "Rosario Castellanos" y decenas de organizaciones de atención a diversas problemáticas en el estado.

Diversas agrupaciones de jóvenes (universitarios, punks, anarcos, etc.) de las colonias, grupos de ciudadanos y vecinos de barrios de la ciudad se sumaron al movimiento así como organizaciones indígenas tales como Servicios del Pueblo Mixe (SER), la Unión de Organizaciones de la Sierra Juárez de Oaxaca (UNOSJO), la Unión de Comunidades Indígenas de la Sierra Norte del Istmo (UCIZONI), el Frente Indígena Oaxaqueño Binacional (FIOB). En el proceso, se formaron nuevas organizaciones: la Coordinadora de Mujeres de Oaxaca y la Coordinadora Estudiantil (cfr. Martínez Vásquez 2007: 69ss.).

De acuerdo también con Víctor Raúl Martínez Vásquez, se pueden identificar distintas vertientes en este conjunto de organizaciones sociales. Una vertiente sindicalista estructurada, con amplia experiencia, agrupadas en el FSODO; organizaciones de la izquierda social con demandas económicas identificada con el socialismo, algunas de ellas agrupadas en la Coordinadora por la Unidad Nacional contra el Neoliberalismo. Una segunda que agrupa a organizaciones civiles inscritas en la lógica de la sociedad civil, con agendas puntuales y diversas pero con coincidencias en los temas de inclusión, participación, justicia y democracia. Se pueden incluir aquí las CEBS identificadas con los derechos humanos. La tercera indígena identificada con los acuerdos de San Andrés y reivindicando posiciones culturalistas, agrarias, de poder local autónomo y pluralismo jurídico. Una cuarta urbana conformada por grupos de colonos y vecinos con demandas de servicios, protección del patrimonio histórico y cultural, condiciones de vida urbana. La quinta compuesta por distintas expresiones políticas como la izquierda parlamentaria, grupos y personas identificadas con el PRD, el PT y Convergencia. Otros con posiciones de izquierda revolucionaria como el FPR. Finalmente, los marginados urbanos: chavos banda y niños de la calle (cfr. Martínez Vásquez 2007: 73ss.). 
cada uno de los subsistemas de la APPO tiene, aparte de las orientaciones generales de comunicación y acción, orientaciones particulares que, en determinados momentos, pueden ser compatibles y, en otros, divergir y entrar en contradicción entre sí. De esta manera, el segmento formado por los miembros del magisterio orienta sus comunicaciones y acciones colectivas típicamente de acuerdo a la lucha sindical, la negociación y el conflicto propios del sistema político institucional (estatal y federal). En cambio, los segmentos de las organizaciones populares y de los sectores no organizados de la población orientan las suyas típicamente fuera y en contra del sistema político. ${ }^{9}$ En su conjunto, esto generó grandes problemas de coordinación y dirección en el sistema de protesta, pero también una gran capacidad de movilización, conflicto y negociación, así como de aprendizaje colectivo y de innovación de los repertorios de protesta, tanto en los espacios sociales como en los institucionales, que depararon grandes dificultades a los oponentes del sistema de protesta (gobiernos estatal y federal, contra-movimiento local) para lidiar con la APPO.

\section{El pueblo toma la palabra: el contexto de la toma de los medios de difusión}

Como sucedía tradicionalmente desde hace un poco más de dos décadas en Oaxaca, los maestros, miembros de la Sección XXII del SNTE, iniciaron su ciclo de movilizaciones el $1^{\circ}$ de mayo de 2006 para demandar mejoras saláriales y laborales de diferente orden con el gobierno de Oaxaca. ${ }^{10}$ La negociación entre el gremio magisterial y el gobierno resultaron especialmente difíciles en ese año. Como medida de presión, los 70 mil maestros decidieron establecer el 22 de ese mismo mes un "plantón" en el zócalo de la ciudad hasta que se diera satisfacción cabal al contenido de su "pliego petitorio". Debido a que ninguna de las partes cedía en sus demandas, el diálogo quedó roto. En consecuencia, los docentes paralizaron prácticamente la ciu-

9 Lo cual no significa que no se vinculen y, posteriormente, entablen diálogos y negociaciones con los actores y las instituciones del sistema político, como es el caso de las organizaciones populares.

10 Sobre la historia de la Sección XXII del SNTE, véase Yescas Martínez/Isidoro y Zafra (2006). Para la organización misma del gremio magisterial, tanto a nivel nacional como en Oaxaca, consúltese Armenta Muñoz (2005). 
dad. Como respuesta, las autoridades estatales decidieron desalojar violentamente el zócalo en la madrugada del 14 de junio de 2006. Los maestros resistieron a la policía y, con el apoyo inesperado de una parte significativa de los ciudadanos de Oaxaca, logrando recuperar la plaza central hacia las diez de la mañana. Tres días después, una coalición impresionante de organizaciones sociales y políticas de diferente signo ideológico, liderada por el magisterio, decidió constituir lo que se conocería como la Asamblea Popular de los Pueblos de Oaxaca. Su objetivo principal era la renuncia inmediata del gobernador Ulises Ruiz Ortiz.

A partir de entonces y hasta finales de noviembre 2006, la APPO controló prácticamente la ciudad de Oaxaca. Por esta razón, las autoridades públicas de todos los niveles (municipal, estatal y federal), así como los representantes de los poderes legislativo y judicial, dejaron de ejercer sus funciones.

Conforme escalaba la polarización entre la APPO y el gobierno de Oaxaca, el tratamiento informativo de los medios de difusión estatal y nacional mostraba un creciente rechazo hacia el plantón del magisterio y a la revuelta popular de la asamblea (Zires 2009).

Justo en este contexto, en el que la información mediática se había convertido en un recurso gubernamental para desprestigiar a los grupos contestatarios, tuvieron lugar una serie de tomas de medios de difusión por parte de los appistas. La represión del 14 de junio de $2006,{ }^{11}$ que incluiría, como enseguida veremos, la interrupción, por varias semanas, de las transmisiones de Radio Plantón, dio lugar, unas horas más tarde, a la ocupación de Radio Universidad por parte de los estudiantes de la Universidad Autónoma Benito Juárez de Oaxaca (UABJO). Un mes y medio después, el $1^{\circ}$ de agosto, tras la denominada "marcha de las cacerolas", un nutrido grupo de mujeres se apropiaría de las instalaciones de la radio y la televisión estatales. Veinte días más tarde, después de la destrucción de sus antenas de transmisión, los appistas se apoderarían sorpresivamente de 12 radiodifusoras comerciales en la ciudad de Oaxaca, de las cuales sólo dos, Radio Oro y Radio La Ley, operarían varias semanas consecutivas. No

11 Entre junio y diciembre de 2006, 23 personas fueron víctimas mortales de la violencia política y cientos más de violaciones a sus derechos humanos. Al respecto, pueden consultarse CCIODH (2007) y Sotelo Marbán (2008). 
fue sino hasta los días finales de noviembre que la última radiodifusora tomada, Radio Universidad, dejaría de emitir su señal tras resistir varios días la violenta represión de la Policía Federal Preventiva (PFP).

\section{Las funciones sistémicas de los medios de difusión en la APPO}

Con fines analíticos, resulta útil distinguir tres tipos de medios de difusión. ${ }^{12}$ Los autogestionados (como Radio Plantón), los ocupados (como Radio Universidad, Canal 9 de TV Oaxaca y las radiodifusoras comerciales, como Radio La Ley o Radio Oro, y las radios comunitarias como, por ejemplo, en el municipio de Zaachila) y los alternativos e independientes (como Ojo de Agua, Indymedia, y los diarios La Jornada y Noticias). Lo que aquí propongo es que se pueden entender a los medios autogestionados y ocupados como un "subsistema" de la APPO. Los medios alternativos e independientes los trataré como un "cuasi subsistema", ya que, si bien tienen una existencia anterior a la asamblea, colaboraron estrechamente con la $\mathrm{APPO}$, por lo que de facto asumieron funciones sistémicas para ésta. ${ }^{13}$

Como subsistema especializado, el conjunto de los medios de difusión en cuestión cumplió cinco funciones para la APPO. En relación con su entorno, difunden, primero, las razones y los objetivos de la protesta appista para informar al público telespectador y radioescucha ${ }^{14}$ con el fin de contrarrestar lo que consideraban una versión parcial, malintencionada y propagandística del conflicto oaxaqueño difundida por los medios de comunicación gubernamentales (estatal y federal), las cadenas televisivas nacionales (TV Azteca y Televisa) y los diarios de circulación nacional y estatal en aras de desacreditar sus movilizaciones contestatarias. En segundo término, al difundir la versión del conflicto de la APPO más allá del territorio oaxaqueño, abrían, por un lado, un espacio de denuncia de la repre-

12 Sobre el concepto de "medios de difusión", véase Luhmann (1998), en especial el capítulo 2.

13 En sentido estricto, Ojo de Agua debería ser incluido dentro de la clasificación como "subsistema", porque participó en la APPO a través de la formación del colectivo Mal de Ojo y con muchos más miembros y colaboradores que los integrantes de Ojo de Agua.

14 Si consideramos a los diarios La Jornada y Noticias, entonces debemos incluir al público lector. 
sión gubernamental para llamar la atención de la opinión pública (nacional e internacional) y, así, proteger a los appistas de mayores agresiones; y, por el otro, creaban la posibilidad de lograr apoyos y alianzas de actores externos o de la población oaxaqueña aún no movilizada.

En tercer lugar, los medios de difusión ${ }^{15}$ contribuyeron, internamente, a generar una perspectiva de observación del sistema de protesta, que le permitiera, mediante esquemas cognitivos y normativos, construir significativamente la realidad y dotar de sentido a los eventos y las comunicaciones e interacciones de los diferentes participantes en el conflicto. En cuarto término, al informar a los participantes en la protesta (tanto a personas y grupos no organizados como a los militantes miembros de organizaciones populares integrantes de la APPO) acerca del estado que guardaba, en un determinado momento, el conflicto y las negociaciones con autoridades federales o al promover iniciativas de movilización (por ejemplo, participar en una marcha o resguardar determinada barricada), los medios de difusión fungían como mecanismos internos de coordinación de las comunicaciones e interacciones sistémicas. En efecto, la ausencia de una dirigencia plenamente reconocida, de una estructura organizativa institucionalizada y funcionalmente efectiva y de mecanismos intra-sistémicos de control, supervisión y comunicación; y frente al hecho de la participación masiva de personas y grupos no miembros de las organizaciones sociales sumadas a la APPO, que -a diferencia de los appistas militantes en organizaciones populares (como FPR, NIOAX o la Sección XXII del magisterio)- no seguían las orientaciones de dirigencias organizacionales, ni estaban sometidas a los mecanismos de control internos de estas. Esta cuarta función de los medios de difusión resultó fundamental para promover la participación constante en las diferentes formas de la movilización contestataria. Con sus comunicaciones, los medios de difusión appistas contribuyeron, en quinto y último lugar, a conformar una identificación entre los participantes de la protesta.

15 Aquí me refiero únicamente a aquellos medios de difusión autogestionados y ocupados por la APPO, y no a los alternativos e independientes. 
Por razones de espacio voy a centrar mi atención en cuatro medios de difusión: Radio Plantón, Radio Universidad, Ojo de Agua y Canal 9 , que caracterizaré sólo con trazos muy rápidos.

Radio Plantón es la radiodifusora de la Sección XXII del magisterio. Empezó a operar en mayo de 2005. Sus transmisiones diarias incluían noticias, música, entrevistas y toda suerte de programas de análisis y culturales desde una visión de izquierda.

Como su nombre lo indica, Radio Universidad es la radiodifusora de la UABJO, que tenía ya años operando. Después del intento de desalojo de los maestros del zócalo, la aprehensión de algunos locutores de Radio Plantón y la destrucción parcial de su equipo de transmisión, los estudiantes universitarios tomaron la radio ese mismo día para apoyar a los maestros. En ese momento, Radio Universidad se incorporó a la APPO como componente de uno de sus subsistemas.

Por otro lado, fundado en 1998, Ojo de Agua es un centro de producción de documentales que trabaja, particularmente, con comunidades y organizaciones indígenas de Oaxaca y Puebla. El proyecto de esta pequeña asociación se conforma de tres áreas: capacitación, producción y difusión, que se dirigen a potenciar las capacidades comunicativas y el aprendizaje y uso de tecnologías de la comunicación de los indígenas.

Finalmente, el Canal 9 de la televisión del estado de Oaxaca se incorporó al subsistema de la APPO tras ser tomado por un nutrido grupo de mujeres, el 1 de agosto, después de realizar una marcha en contra del gobierno de Ulises Ruiz.

\section{Organización, operación y programación de los medios de difusión}

La "toma de los medios" no fue exclusivamente un asunto político y judicial; para los ocupantes significó, además, un verdadero desafío intelectual y técnico, porque, en la mayoría de los casos, desconocían la operación de los aparatos de transmisión radiofónica y televisiva. El caso del Canal 9 ejemplifica muy bien esta situación. Las mujeres que ocuparon sus instalaciones no abrigaban, unas horas antes, ninguna intención de operarlo. Su propósito era más modesto: obtener 
el compromiso de que se les entrevistara para que pudieran expresar las razones de su protesta.

Sin embargo, las mujeres se apropiaron, de manera sorpresiva, de la televisora y desalojaron al personal de la misma. De inmediato surgió la interrogante: ahora que se tiene el medio, ¿qué hacer con él? La primera respuesta consistió en coordinarse entre ellas para, después, decidir sobre el objetivo central de su acción:

En las primeras horas de la toma [del Canal 9], había una tensión muy fuerte, porque había tanta gente y no sabíamos quién era quién y cuáles [eran] sus intenciones. En fin, alrededor de las 7 de la tarde nos organizamos, en la explanada de las instalaciones, a pesar de que no nos conocíamos. Como la mujer es, en general, muy disciplinada, lograron crear diferentes grupos de seguridad, comida, higiene, solidaridad y economía (entrevista con Nancy Mota, integrante de COMO, 27 de julio de 2009).

Para la abrumadora mayoría de las ocupantes, el mundo de la teledifusión era tierra incógnita: muchas no habían visto antes, por ejemplo, tantos monitores, consolas de control, cámaras, platos, etc; y mucho menos sabían cuál era su función y cómo se utilizaban. Se encontraban estupefactas, ya que justo en esos momentos empezaron a atisbar las dimensiones de su intrepidez y el tamaño de su responsabilidad: "Nos reíamos mucho porque decíamos: "ya tomamos la televisión, pero y ahora qué [hacemos con ella]" (entrevista con Nancy Mota). De nueva cuenta, la solución a sus incertidumbres se resolvió por medio de la auto-organización: "Entonces, se decide hacer grupos de producción, televisión y radio y quién operaría los aparatos y grabar las conferencias y todas las marchas" (entrevista con Nancy Mota). Afortunadamente, entre los appistas presentes en el Canal 9, se encontraban algunos estudiantes universitarios que poseían algunas nociones básicas en el uso y la función de los aparatos:

En lo personal, estudié la carrera de tecnología educativa. Tuvimos la suerte que algunos chavos independientes de la Asamblea Universitaria tenían un poco de conocimientos [en la materia], porque estudiaban para técnicos. Había otro chavo que había trabajado en una radio comercial. Todos juntos empezamos a picar los aparatos y ver cómo funcionaban. Lo bueno es que [los operadores] habían dejado al aire la señal... Yo formé parte de la producción de la televisión. Ya que teníamos el medio en nuestras manos, había que reconocer su importancia y sacarle provecho. Teníamos que dar información argumentando adecuadamente y sin titubear. Hacia las 9:30 ya habíamos preparado todo y estábamos listas para transmitir. Teníamos que salir pronto al aire, porque ya se empezaba a escuchar el golpeteo por parte de todas 
las radios [pro oficialistas oaxaqueñas]. Se decía que [los policías] iban a ir por nosotras, porque [la toma de la estación] era un delito federal. Dos amigos se ocuparon del master y el switscher, y yo de la dirección de cámaras. Un grupo de compañeras amas de casa, obreras, estudiantes y militantes de organizaciones sociales se sentaron en el escenario para salir al aire. ¡Era el primer programa y era tan emotivo ver a la mujer oaxaqueña! (entrevista con Nancy Mota).

En relación al tema de la organización del trabajo y el aprendizaje, el caso de Ojo de Agua resulta, particularmente interesante, porque se trata de un centro especializado en la producción de documentales en video. Aquí se puede observar cómo el involucramiento en la dinámica de la movilización y la protesta modifica las rutinas organizativas. Debido a su experiencia profesional, Ojo de Agua se convirtió en un espacio de encuentro, intercambio y colaboración con otros medios. Inclusive, fungió como plataforma para el procesamiento de información:

Compañeros, conocidos desde hace tiempo, nos visitaban y traían fotos, videograbaciones y material, que rápidamente lo recibíamos y empezábamos a editar en la oficina y, después, lo subíamos a la página de Indymedia. Así es como surgió nuestro involucramiento con el movimiento social. De pronto, nos dimos cuenta de que todos estábamos juntos respondiendo a lo que estaba sucediendo. En este sentido, nuestra participación no fue planeada (entrevista con Joaquina [pseudónimo], integrante de Ojo de Agua, 22 de julio de 2009).

Por otra parte, al aprendizaje del manejo técnico de los aparatos, se agregó un nuevo reto para los ocupantes de los medios de difusión. Los appistas tomaron conciencia muy pronto de la importancia y la oportunidad política sin igual que representaba controlar dichos medios. Por esta razón, casi de inmediato surgieron disputas ideológicas y de poder entre ellos mismos: ¿quiénes deberían hacerse cargo de la transmisión y producción de programas radiofónicos y televisivos?

Para las grandes organizaciones populares, el control sobre los medios de difusión ocupados implicaba aumentar su influencia en la dirección de la APPO y su capacidad de reclutamiento de posibles nuevos miembros. La situación de Radio Universidad ilustra muy bien este punto. Tras la toma de sus instalaciones, su barra programática habitual se modificó. Entonces, se creó una barra alternativa y un cronograma para organizar los tiempos y los turnos de operación y transmisión por facultad universitaria. Conforme pasaba el tiempo, diferentes organizaciones estudiantiles -como la Unión de Jóvenes 
Revolucionarios de México (UJRM) o el Frente de Estudiantes Universitarios (FEU), que, a su vez, formaban parte de organizaciones populares y políticas mayores con intereses, también, en la universidad- empezaron a sumarse a las tareas radiofónicas y a disputarse la conducción y la definición de los contenidos de los programas; es decir, el sentido de la radio y el uso que, según ellos, debería darsele en la "lucha política". Por supuesto, esto ocasionó tensiones en el "equipo" de Radio Universidad: un sector, identificado con las organizaciones populares y políticas, se proponía utilizar a la radio sólo como un "medio de propaganda y agitación", mientras que otro, de estudiantes independientes,

quería darle más contenido y mensaje a la comunicación para que [sembrara] algo [más] en la gente. No se trataba de dar un mensaje [propagandístico] directo, sino de generar análisis y de que la gente también hiciera propuestas. Nosotros pensábamos que teníamos que canalizar así todo el enojo y el llanto que la gente expresaba en las denuncias (entrevista con Julia [pseudónimo], locutora de Radio Universidad, 15 de abril de 2009).

A pesar de estas disputas ideológicas y por el poder, Radio Universidad y Canal 9 lograron armar, con muy escasos recursos, improvisación y mucho deseo de aprender, una barra de programas variada e interesante para un público segmentado (urbano y rural, infantil, juvenil y adulto), en las que se incluían programas culturales, noticiosos y de análisis. Buscando que diferentes sectores de la APPO, como el magisterial, el de las mujeres, los indígenas, los jóvenes, los universitarios o el de las Organizaciones No Gubernamentales (ONG's) tomaran el micrófono o aparecieran frente a las cámaras.

Al ser un centro de producción de documentales, la situación de Ojo de Agua era diferente a la de otros medios de difusión, ya que, abandonando su rutina laboral e incursionando en actividades un tanto ajenas a sus objetivos principales, empezó a trabajar de facto como una oficina de redacción.

Había compañeros en la calle haciendo entrevistas; otros salían en la noche a grabar lo que pasaba en las barricadas o simplemente a platicar con las personas... Otros compañeros se quedaban en las oficinas para editar el material en cuanto llegara. Pero no había algo así como un jefe de redacción; prácticamente se subía [a la red] todo el material que nos llegaba, porque eran testimonios importantes de violaciones [a los derechos humanos] (entrevista con Joaquina [pseudónimo], integrante de Ojo de Agua, 22 de julio de 2009). 


\section{Alterando la lógica mediática}

Si bien "la toma de medios de difusión" por parte de la APPO fue algo significativo e importante para su lucha, esta no ha sido empero una experiencia excepcional entre los movimientos sociales. En efecto, muchos otros lo han hecho con anterioridad. Lo realmente notable y novedoso del caso oaxaqueño es que la APPO modificó, por un tiempo, la relación de los medios con el público, el modo y el sentido de operación de los mismos.

Efectivamente, el público cambió su papel tradicional de radioescucha pasivo por el de comunicador desde las calles, plazas y barricadas. En este sentido, las radios se convirtieron en un medio de difusión autogestionado por la APPO no sólo porque sus instalaciones hayan sido ocupadas y operadas por sus simpatizantes, sino, sobre todo, porque el "público radioescucha" appista asumió activamente la tarea de informar y de usar el medio como instrumento de comunicación al interior y al exterior de la APPO. La experiencia de Radio Universidad resulta ejemplar:

[En la radio] se construyó una red entre los que estaban en la radio dándole vida y toda la gente que llamaba [telefónicamente] y enviaba mensajes [de texto] como, por ejemplo, "aquí hay una caravana de la muerte", "estamos viendo policías que pasan balaceando", etc. Incluso había un programa que se llamaba Las Barricadas, que pasaba desde las 10 de la noche hasta [muy altas horas de la madrugada]. En él, la gente informaba sobre lo que estaba pasando $y$, también, pedía informes sobre otros sucesos... La radio se retroalimentaba por toda la información que pasaba la gente y reaccionaba a las demandas de la gente (entrevista con Anselmo [pseudónimo], locutor de Radio Universidad, 24 de septiembre de 2008).

Quizá la toma del Canal 9 de la televisión oaxaqueña da cuenta, de manera más nítida, de la modificación radical de la lógica mediática convencional. Primero, porque las mujeres appistas asumen directamente el control técnico de la producción y difusión de los programas, así como el resguardo, mediante barricadas, de las instalaciones transmisoras. Por si esto fuera poco, segundo, las appistas no sólo asumen el papel de generadoras y transmisoras de comunicación mediática, sino que, además, sus voces se escuchan en la radio y sus imágenes se ven en la televisión. De tal suerte, la diferencia entre los roles de emisor y público se dislocaron y fusionaron. Las mujeres transmiten 
para sí mismas y para el conjunto de la población appistas. En tercer lugar, el "pueblo" aparece, se ve y se reconoce a sí mismo más allá de las imágenes en el que se le muestra como objetos de información policíaca, de políticas de asistencia pública o de folclor, burla, denigración y discriminación, como se acostumbra en la televisión pública y comercial (vid. Mal de Ojo TV/Contraimagen 2007). Con ello fueron subvertidos, temporalmente, los códigos estéticos y lingüísticos convencionales en la televisión y la radio (Zires 2009).

Al abrirse el espacio mediático a las voces y demandas de amplios sectores de la población se sentaron las bases para lograr una identificación emocional y discursiva con la APPO. En efecto, la expresión directa y sin censura de todo tipo de sentimientos a través de los canales radiofónico y televisivo producía efectos de catarsis, tanto en el que exponía su dolor personal como en el público. Además, para muchos de los que se comunicaban con las radiodifusoras, vivían, quizás por primera vez en su vida, la experiencia de que su opinión y sus sentimientos se escucharan y se les considerara como valiosos e importantes. Escuchar su voz en la radio o ver su imagen en la televisión significó para muchos un reconocimiento a su persona y a su dignidad. Todo ello generó fuertes lazos de identificación con la APPO y la "Comuna de Oaxaca".

Por otro lado, los medios de difusión se convirtieron en espacios públicos virtuales. La experiencia de Radio Universidad ilustra muy bien este fenómeno: ésta no fue sólo un espacio de transmisión de información, sino, también y de manera prominente, de deliberación política. Ante la imposibilidad de una participación directa de la mayoría de los appistas en las asambleas llevadas a cabo en el zócalo de Oaxaca, la radiodifusión contribuyó a construir foros de opinión y delinear posibles proyectos políticos.

[Se discutía mucho que el sentido de la lucha] que no era sólo derrocar a Ulises Ruiz, sino que había que buscar más allá de ese primer paso. Había que retomar lo que se estaba haciendo: la construcción de relaciones [sociales] distintas y de un poder popular. Primero se convirtió en una consigna, "todo el poder al pueblo". Luego fue analizado también por [el pueblo] y surgió [la opinión] de que el poder no nos lo va a dar nadie: ya lo estamos ejerciendo. Los locutores empezaron a hablar de qué es el poder popular. Incluso había un programa en el que regalábamos un disco con las mejores canciones del movimiento a la gente que llamara y nos dijera qué es el poder popular. Mucha gente decía que se trataba de tomar el gobierno; otros hablaban, en cambio, de las barri- 
cadas, las reuniones o las asambleas (entrevista con Anselmo [pseudonimo], locutor de Radio Universidad, 24 de septiembre de 2008).

En resumen, el sentido de la comunicación de la radio y la teledifusión fue modificado para ponerla al servicio de la lucha popular appista en contraposición a las lógicas mercantiles y gubernamentales hasta entonces dominantes.

Por otra parte, la toma de los medios puede ser entendida como parte de un proceso de construcción de "medios alternativos y populares". En este sentido, el equipo de Radio Plantón comprende su trabajo como la "necesidad de defensa del derecho constitucional de información de la población". En Radio Plantón se tiene la convicción de que la radio habría que asumir la función de construir ciudadanía para "organizar a la sociedad" (vid. SNTE-Sección XXII/ CNTE/Radio Plantón 2007). Este tipo de periodismo se ejerce como una actividad política, que busca cuestionar el monopolio de la construcción de la verdad informativa de las grandes corporaciones de los medios de comunicación.

Lo anterior tiene consecuencias en la manera de comprender el proceso informativo, pues este se hace más horizontal, ya que abre la posibilidad de que cualquier persona pueda aportar textos, audios e imágenes, que den cuenta de historias y la manera en que la viven los involucrados en los eventos "desde dentro". La forma en que operó Mal de Ojo en los días del conflicto ejemplifica muy bien lo anterior:

Muchas de estas personas [que ponían material a nuestra disposición] no eran profesionales. Simplemente tenían una cámara o, inclusive, un teléfono celular y sacaban videos o fotos (entrevista con Joaquina [pseudónimo], integrante de Ojo de Agua, 22 de julio de 2009).

\section{Conclusiones}

En la medida en que los medios de difusión proappistas se revelaron como un poderoso factor de formación de opinión pública y movilización contestataria, el gobierno estatal no desperdició tiempo ni ocasión para descalificarlos y censurarlos de diferentes maneras. Inclusive puso en operación, de manera clandestina e ilegal, Radio Ciudadana y la página web "oaxacaenpaz". Estas criminalizaron el movimiento y convocaron a radioescuchas e internautas a denunciar a líderes y miembros de la APPO, a agredirlos y hasta a eliminarlos físicamente. Para ello, hacían públicas sus fotografías y direcciones 
particulares y de trabajo, así como los nombres de sus familiares. Con un discurso racista y clasista orientado a provocar odio, calificaban a los appistas de "criminales, terroristas, malvivientes, indios, sucios y feos". En su opinión, todos ellos merecerían ser asesinados para que los "auténticos" y "bien nacidos" oaxaqueños y demás "ciudadanos ejemplares" pudieran vivir por fin en paz y orden (vis. Martínez Vásquez 2007: 96, 105s., 180s; Beas Torres 2007: 184s.; Méndez et al. 2009: 147s.). En los últimos días de noviembre, todos los medios de difusión tomados fueron sacados del aire mediante una represión masiva orquestada por la Policía Federal Preventiva.

Las estaciones de televisión y radio tomadas fueron, primero, bloqueadas y, después, recuperadas en su totalidad por las autoridades públicas federales y estatales, con lo que se desestructuraría, de manera significativa, el subsistema de difusión de la APPO; sin embargo, este no dejó de existir y de operar del todo, aunque en menor escala y bajo nuevas condiciones. En efecto, Radio Plantón ha seguido trasmitiendo, aunque su señal es interferida con frecuencia. Asimismo, Ojo de Agua ha coproducido hasta la fecha, bajo la denominación Mal de Ojo, una serie de documentales. Y si tomamos en cuenta a los diarios Noticias y La Jornada, la APPO ha mantenido, hasta el día de hoy, cierta presencia mediática y capacidad de divulgar sus acciones, opiniones y proyectos.

Por otro lado, teniendo en cuenta la heterogeneidad, pluralidad política-ideológica y los conflictos entre las diferentes organizaciones y grupos que componían la asamblea, habría que preguntarse, entonces, cómo fue posible que, contra toda probabilidad, se haya generado un discurso relativamente "homogéneo" y una perspectiva de observación "compartida" en el subsistema de difusión de la asamblea. La respuesta resulta, necesariamente, compleja. En primer lugar, lo "común" entre los diferentes "elementos" que conformaban al subsistema de difusión, en particular, y al sistema de protesta, en general, era el esquematismo básico $\mathrm{APPO} /$ gobierno entre todos compartido. A la manera de la relación entre código y programa en los sistemas funcionales, este era reespecificado por cada uno de los involucrados (elementos del subsistema o del sistema) de acuerdo a semánticas de protesta singulares, que fueron elaboradas por dichos elementos ya sea desde el lugar de la experiencia individual en el conflicto (por 
ejemplo, el discurso del "pueblismo" de los barricaderos) ${ }^{16}$ o con anterioridad a su incorporación a la asamblea. Expresado de otra manera, la oposición discursiva fundamental "APPO versus gobierno" fungía como un lenguaje común, el cual tenía diferentes dialectos para observar, describir y explicar la realidad. Así, a pesar de la multiplicidad de las esferas de deliberación colectiva al interior del sistema de protesta (por ejemplo, las asambleas de las barricadas barriales, los muros intervenidos por los colectivos de artistas con su protesta gráfica, etc.), las diversas observaciones de los participantes de estos foros conservaban un "aire de familia".

Además, esta relativa "homogeneidad" en la perspectiva de observación era resultado, asimismo, de la interacción conflictiva entre la asamblea y el gobierno. En efecto, con el fin de obtener mayores posibilidades de éxito en su lucha político-social, al interior de la APPO se exhortaba (e incluso coaccionaba) a la "unidad" frente al "enemigo". De tal suerte, hacia fuera las posiciones "oficiales" de la asamblea eran fijadas por sus voceros, a pesar de que hacia dentro resultaban polémicas, por decir lo menos. En todo caso, el observador externo percibía en estas comunicaciones $-\mathrm{y}$, en consecuencia, en las del subsistema de difusión- un "discurso appista" más o menos coherente.

Después del sangriento restablecimiento del "orden institucional", Ulises Ruiz reconoció la importancia del control de los medios de difusión e inició una costosa campaña mediática, a nivel estatal y nacional, para "mejorar" la imagen de su gobierno y propagar la idea de que en "Oaxaca no pasa nada" y se "respira un clima de paz social". A pesar de la propaganda oficialista, las protestas sociales continuaron en los años siguientes, aunque de manera descoordinada. Sin embargo, los agravios acumulados pudieron, paradójicamente, encontrar una vía de expresión en las elecciones para gobernador y congreso local en julio de 2010. En efecto, gracias a la alianza opositora, que gozaría del apoyo del magisterio y de muchas de las organizaciones populares que conformaron la APPO, por primera vez en Oaxaca se lograría una alternancia en el poder después 80 años de gobiernos priístas.

16 Sobre el tema, véase Estrada Saavedra (2010), en particular pp. 923ss. 


\section{Bibliografía}

Ahlemeyer, Heinrich W. (1989): "Was ist eine soziale Bewegung? Zur Distinktion und Einheit eines sozialen Phänomens”. En: Zeitschrift für Soziologie, 18, 3, pp. 175-191.

- (1995): Soziale Bewegungen als Kommunikationssystem. Einheit, Umweltverhältnis und Funktion eines sozialen Phänomens. Opladen: Leske + Budrich.

Armenta Muñoz, Aldo (2005): El sindicalismo mexicano frente a la reforma del Estado. El impacto de la descentralización educativa y el cambio político en el Sindicato Nacional de Trabajadores de la Educación 1992-1998. México, D.F.: Universidad Iberoamericana.

Bailon Corres, Jaime (1999): Pueblos indios, élites y territorio. Una historia política de Oaxaca. México, D.F.: El Colegio de México.

Beas Torres, Carlos (ed.) (2007): La batalla por Oaxaca. Oaxaca: Ediciones Yope Power.

Bolos, Silvia (coord.) (2003): Participación y espacio público. México, D.F.: Universidad Ciudad de México.

- (2008): Mujeres y espacio público: construcción y ejercicio de la ciudadanía. México, D.F.: Universidad Iberoamericana.

Bolos, Silvia/Estrada Saavedra, Marco (2010): "Protesta social y democratización: un estudio sociológico sobre la constitución, organización y movilización de la Asamblea Popular de los Pueblos de Oaxaca (2005-2010)". En: Estudios Sociológicos, vol. XVIII, núm. 82, pp. 231-254.

CCIODH (Comisión Civil Internacional de Observación por los Derechos Humanos) (2007): Informe sobre los hechos de Oaxaca. Barcelona: CCIODH-UACM.

Cortés, Joel Vicente (coord.) (2006): Educación, Sindicalismo y gobernabilidad en Oaxaca. Oaxaca: SNTE.

Cunill, Nuria (1999): Repensando lo público a través de la sociedad. Nuevas formas de gestión pública y representación social. Caracas: Nueva Sociedad.

Denham, Diana/C.A.S.A Collective (2008): Teaching Rebellion. Stories from the Grassroots Mobilization in Oaxaca. Oakland: P.M. Press.

Estrada Saavedra, Marco $\left({ }^{2} 1995\right)$ : Participación política y actores colectivos. México, D.F.: Universidad Iberoamericana/Plaza y Valdés.

- (2008): Sistemas de protesta. Manuscrito inédito.

- (2010): "La anarquía organizada: las barricadas como el subsistema de seguridad de la Asamblea Popular de los Pueblos de Oaxaca". En: Estudios Sociológicos, vol. XVIII, núm. 84, pp. 903-939.

Giarracca, Norma (2008): Cuando hasta las piedras se levantan. Oaxaca, México, 2006. Buenos Aires: Antropofagia.

Hellmann, Kai-Uwe (1996): Systemtheorie und neue soziale Bewegungen. Identitätsprobleme in der Risikogesellschaft. Opladen: Westdeutscher Verlag.

- (1998): "Systemtheorie und Bewegungsforschung. Rezeptionsdefizite aufgrund von Stildifferenzen oder das Außerachtlassen von Naheliegendem". En: Rechtshistorisches Journal, 17, pp. 493-510. 
- (2000): “... und ein größeres Stück Landschaft mit den erloschenen Vulkanen des Marxismus. Oder: Warum rezipiert die Bewegungsforschung Luhmann nicht?". En: De Berg, Henk/Schmidt, Johannes (eds.): Rezeption und Reflexion. Zur Resonanz der Systemtheorie Niklas Luhmanns außerhalb der Soziologie. Frankfurt am Main: Suhrkamp, pp. 411-439.

Japp, Klaus P. (1984): "Selbsterzeugung oder Fremdverschulden. Thesen zum Rationalismus in den Theorien sozialer Bewegungen". En: Soziale Welt, 35, 3, pp. 313-329.

- (1986a): "Kollektive Akteure als soziale Systeme?". En: Unverferth, HansJürgen (ed.): System und Selbstproduktion. Zur Erschließung eines neuen Paradigmas in den Sozialwissenschaften. Frankfurt am Main/Bern/New York: Peter Lang, pp. 166-191.

- (1986b): "Neue soziale Bewegungen und die Kontinuität der Moderne". En: Berger, Johannes (ed.): Die Moderne-Kontinuitäten und Zäsuren (Soziale WeltSonderband 4). Göttingen: O. Schwartz, pp. 311-333.

- (1990): "Das Risiko der Rationalität für technisch-ökologische Systeme". En: Halfmann, Jost/Japp, Klaus Peter (eds.): Riskante Entscheidungen und Katastrophenpotentiale. Elemente einer soziologischen Risikoforschung. Opladen: Westdeutscher Verlag, pp. 34-60.

Luhmann, Niklas (1987): Soziale Systeme. Grundriss einer allgemeinen Theorie. Frankfurt am Main: Suhrkamp.

- (1992): Sociología del riesgo. Jalisco: Universidad Iberoamericana/Universidad de Guadalajara.

- (1996): Protest. Systemtheorie und soziale Bewegungen. Herausgegeben und eingeleitet von Kai-Uwe Hellmann. Frankfurt am Main: Suhrkamp.

- (1998): Die Gesellschaft der Gesellschaft. Frankfurt am Main: Suhrkamp.

- (2005): "Interaktion, Organisation, Gesellschaft". En: Soziologische Aufklärung 2. Aufsätze zur Theorie der Gesellschaft. Wiesbaden: VS, Verlag für Sozialwissenschaften, pp. 9-24.

Mal de Ojo TV/Contraimagen (2007): Morena. DVD. Oaxaca, marzo s/e.

Martínez Vásquez, Víctor Raúl (2007): Autoritarismo, movimiento popular y crisis política: Oaxaca 2006. México, D.F.: UABJO/Instituto de Investigaciones Sociológicas/Centro de Apoyo al Movimiento Popular Oaxaqueño/A.C./EDUCA/ Consorcio para el Diálogo Parlamentario y la Equidad.

- (coord.) (2009): La APPO: ¿rebelión o movimiento social? Oaxaca: $\mathrm{UABJO/Instituto} \mathrm{de} \mathrm{Investigaciones} \mathrm{Sociológicas.}$

Méndez, Citlalli/Kast, Nicole/Cruz, Kiado/Cruz, Yesika (eds.) (2009): Oaxaca 2006: lo vimos, lo vivimos. Narraciones en movimiento. Oaxaca: Oaxaca Libre/ Universidad de la Tierra/Swarthmore College/Medios de Información Alternativos y Revolucionemos Oaxaca.

Neidhardt, Friedhelm (ed.) (1994): “Öffentlichkeit, öffentliche Meinung, soziale Bewegungen”. Kölner Zeitschrift für Soziologie und Sozialpsychologie (Sonderheft $34)$.

Osorno, Diego Enrique (2007): Oaxaca sitiada. La primera insurrección del siglo XXI. México, D.F.: Grijalbo. 
Recondo, David (2007): La política del gatopardo. Multiculturalismo y democracia en Oaxaca. México, D.F.: CIESAS/CEMCA.

SNTE-Sección XXII-Oaxaca/CNTE/Radio Plantón (2007): Radio Plantón otra vez al aire 92.1. DVD. Oaxaca: SNTE-Sección XX.

Sotelo Marbán, José (2008): Oaxaca: insurgencia civil y terrorismo de Estado. México, D.F.: ERA.

Yescas Martínez, Isidoro/Zafra, Gloria (2006): La insurgencia magisterial en Oaxaca. Oaxaca: IEEPO/IISUABJO.

Videohackers (2007): Brad, uma noite mais nas barricadas. DVD. Videohackers/Indymedia/Familia Bastos producciones-Brasil/Producciones IntermediaEspaña, s/e.

Zires, Margarita (2009): "Estrategias de comunicación y acción política. Movimiento social de la APPO”, en: Martínez Vásquez, Víctor Raúl (coord.): La APPO: ¿rebelión o movimiento social? (Nuevas formas de expresión ante la crisis). Oaxaca: UABJO-Instituto de Investigaciones Sociológicas, pp. 161-196. 
